\section{Mensuração da qualidade do comércio de Balsas, MA, por meio da escala RSQ}

\section{Measuring the quality of trade in Balsas, MA, through the RSQ scale}

\author{
Antonia Clara Oliveira1 \\ Jonas Fernando Petry ${ }^{2}$ \\ Gustavo da Rosa Borges3
}

\begin{abstract}
Resumo
Comércio é um segmento de vital importância para o desenvolvimento regional, a economia e as relações de consumo social. Portanto, torna-se indispensável aos comerciantes estudar o comportamento dos consumidores, objetivando sua satisfação, visto que isso pode ocasionar resultados positivos. Em Balsas, MA, conhecer os anseios dos consumidores também é vital para o desenvolvimento comercial e regional, principalmente pelo fato de a cidade ser polo comercial no sul do Estado. Buscando mensurar a qualidade do comércio local, realizou-se uma survey quantitativa com 248 consumidores abordados no centro da cidade. Para a coleta dos dados, utilizou-se uma escala internacional validada, a RSQ (Retail Service Quality), que é apropriada para medir a qualidade do serviço no varejo (DABHOLKAR; THORPE; RENTZ, 1996). Percebeu-se que o consumidor balsense não está satisfeito com os estabelecimentos comerciais da cidade. Verificouse, ainda, por meio de teste-Te ANOVA, que pessoas de menor escolaridade avaliaram mais negativamente $\mathrm{O}$ comércio local, e não houve divergência de opiniões entre moradores nascidos na cidade ou não, inclusive contando o tempo de residência, levando-se a crer que pessoas de fora acabam tendo as mesmas percepções que as nativas. Em relação à escala usada, confirmou-se sua aplicabilidade ao comércio, sendo ela ainda pouco empregada no Brasil.
\end{abstract}

Palavras-chave: Qualidade; Pequenos Comércios;

\begin{abstract}
Trade is a segment of vital importance for regional development, the economy and relations of social consumption. Therefore, it is essential for traders to study the consumer behavior, aiming at his satisfaction, as this can cause positive results. In the city of Balsas, state of Maranhão, knowing the desires of consumers is also vital for business and for regional development, mainly because the city is a commercial hub in the south of the state. Seeking to measure the quality of local trade, a quantitative survey with 248 consumers that circulated in the city center was made. For data collection, a validated international scale was used, the RSQ (Retail Service Quality), which is appropriate for measuring the quality of services in retail (DABHOLKAR; THORPE; RENTZ, 1996). It was possible to notice that the Balsas consumer is not satisfied with the city's shops. TheT-test and ANOVA also showed that people with a lower level of education evaluate more negatively the local trade, and there was no difference of opinion among residents born in the city or outside it, even counting the residence time, leading to believe that people born outside of the city eventually have the same perceptions as the natives. In relation to the scale used, it confirmed its applicability to trade, and that scale is not widely used in Brazil.
\end{abstract}

Key-words: Quality; Small Trades; Consumer satisfaction.

${ }^{1}$ Administradora pela Unibalsas. E-mail: nia.clara 1@,hotmail.com

${ }^{2}$ Doutorando em Administração pela FURB. Mestre em Administração pela Universidade do Estado de Santa Catarina (UDESC). E-mail: jonaspetry@,brturbo.com.br

${ }^{3}$ Doutor em Administração pela FURB; Mestre em Administração pela Unisinos; Docente da UNIPAMPA - Campus Dom Pedrito. E-mail: gustavoborges@,unipampa.edu.br

Artigo recebido em: 19 de abril de 2016. Artigo aceito em 16 de fevereiro de 2017. 


\section{INTRODUÇÃO}

Vivemos em um mundo com constantes mudanças culturais, sociais e econômicas, que são decorrentes principalmente das consequências da globalização econômica e do avanço científico e tecnológico, causando incerteza no mercado, que está cada vez mais dinâmico. Isso certamente impacta nas empresas, exigindo que elas adotem práticas gerenciais que venham a possibilitar melhores resultados e visando à satisfação do cliente. Para que as empresas melhor programem essa conduta, torna-se relevante adotar ações empreendedoras, e essa indicação vale para todos os segmentos: indústria, comércio e serviços. Desses, o comércio é foco de estudo do presente trabalho.

Além dessa classificação, as empresas podem ser distintas pelo tamanho. Chinem (2001) destaca a importância das pequenas empresas para a economia do Brasil, sendo responsáveis pela geração de emprego e renda para a sociedade e carecem de uma gestão mais profissional. Isso inclui as pequenas empresas comerciais, que serão estudadas no decorrer deste trabalho.

Barney e Clark (2007) declaram que gestores devem ter uma visão geral e o modo como eles administram as empresas é fator preponderante para o sucesso delas no mercado. Tomadores de decisões nas empresas, incluindo comerciantes, devem gerenciar seus negócios pensando cada vez mais na satisfação do cliente e buscando novas formas de conquistá-los ainda mais, sendo esse um dos objetivos principais do marketing (KOTLER; KELLER, 2008). Essa necessidade de desenvolver o marketing nas empresas pode torná-las cada vez mais competitivas e contribuir para que elas venham a ter um diferencial, visto que hoje se deve estar sempre procurando identificar e atender de uma melhor forma aos consumidores.

Cabe ressaltar que consumidores são heterogêneos, fazendo cada vez mais que as empresas venham a buscar uma diferenciação para melhor atendê-los. Para tanto, é indispensável a elaboração de produtos e serviços de melhor qualidade (LAUGA; OFEK, 2011).

No entanto, apesar da necessidade de primar pela qualidade dos produtos e serviços prestados por comerciantes, poucos trabalhos científicos têm buscado medir efetivamente a qualidade do comércio central em pequenas cidades do país, especialmente aquelas localizadas no interior do Nordeste, local que ainda carece de 
melhores condições sociais e estudos científicos que contribuam para o seu desenvolvimento.

Nesse sentido, o presente artigo tem por objetivo principal responder ao seguinte questionamento: os consumidores de Balsas/MA percebem a qualidade dos estabelecimentos comerciais da cidade?

Para responder a essa indagação, procurou-se realizar primeiramente um levantamento bibliográfico que pudesse demonstrar indícios de como pesquisar a satisfação dos clientes de estabelecimentos comerciais. Essa busca teórica foi importante para definir o instrumento de coleta a ser utilizado na pesquisa de campo, a qual foi feita com os consumidores do comércio de Balsas, e as respostas são demonstradas ao longo do artigo. Para a coleta dos dados, analisaram-se três instrumentos, a escala SERVQUAL, a SERVPERF e a mais recente escala, a RSQ. A última foi escolhida pelo fato de ser mais atual e por não ser tão explorada como as demais no Brasil. Procurou-se, também, testá-la para a avaliação do comércio local no contexto nacional.

\section{REFERENCIAL TEÓRICO}

\subsection{Atividade Comercial de Pequenas Empresas}

As atividades comerciais de pequenas empresas são importantes para o desenvolvimento regional. Longenecker et al. (1997) destacam que as pequenas empresas contribuem para o bem-estar econômico da nação, já que elas geram empregos, introduzem inovações, estimulam a competição, auxiliam as grandes, produzem bens e, muitas vezes, prestam serviços com eficiência, satisfazendo os consumidores.

Souza e Mazzzali (2008) definem que pequenas empresas são aquelas que possuem recursos financeiros limitados e competem por pequenas fatias no mercado, no entanto buscam sobreviver ou crescer. Elas procuram adotar práticas de empreendedorismo (BARROS; PEREIRA, 2008). Contudo, empresas menores e mais jovens têm maior risco de fechamento do que aquelas consideradas maiores e que já estão bem estabelecidas no mercado (MIZUMOTO; BEDÊ, 2010). Oliveira (1997) manifestou que grande parte das pequenas empresas acaba fechando nos primeiros anos de atividade, e isso ocorre muito pela falta de melhor gestão nas atividades 
empreendedoras.

Isso se torna tão importante que Viapina (2000) descobriu que o sucesso das pequenas empresas está na sua capacidade de adaptar-se ao consumidor, especialmente relacionando-se constantemente com ele e adequando sua loja para satisfazê-lo, entre outros motivos. Chinem (2001) também destaca a importância do marketing e da comunicação com os clientes, já que é possível, por meio dessa interação, obter boa imagem institucional com retornos vantajosos.

Muitos consumidores fazem compras em unidades de varejo buscando sentiremse bem, e isso tende a ocorrer quando se percebem atributos positivos, como: limpeza, organização, atendimento, variedade de produtos, preço, localização e estacionamento (MELO et al., 2012). Borges et al. (2013) verificaram que consumidores preferem comprar em pequenos estabelecimentos em virtude da simplicidade, do preço, do crédito, do atendimento, da inexistência de filas, da qualidade dos produtos, da proximidade com a residência ou o local de trabalho e da informalidade.

Portanto, percebe-se que a satisfação do consumidor é preponderante para o sucesso do negócio, tornando-se relevante sua medição para uma análise gerencial que venha a conhecer as demandas sociais e, futuramente, a implementação de melhorias que contribuam cada vez mais para uma maior satisfação dos clientes.

\subsection{Satisfação do Cliente com Ênfase na Qualidade}

Para uma empresa conquistar clientes e superar a concorrência, é preciso que ela venha a realizar um melhor trabalho de atendimento e satisfação das necessidades do cliente (KOTLER, 2008). O conceito mais básico por trás disso é o das necessidades humanas, que são situações de privação percebida. Incluem necessidades físicas básicas de alimentação, vestuário, abrigo e segurança. As empresas que se destacam são justamente as que conseguem suprir essas necessidades, desejos e as demandas de seus clientes (KOTLER; ARMSTRONG, 2007). "Satisfação consiste na sensação de prazer ou desapontamento resultante da comparação do desempenho (ou resultado) percebido de um produto em relação às expectativas do comprador" (KOTLER, 2008, p. 53). Buscar a satisfação dos consumidores é um conceito muito amplo, visto que as pessoas apresentam diferentes necessidades e desejos (LAS CASAS, 2010).

Muitas empresas procuram propiciar uma alta satisfação aos seus clientes, isso porque se os consumidores estiverem apenas satisfeitos, corre-se o risco de eles estarem 
mais dispostos a mudar se surgir oferta melhor (KOTLER, 2008).

As empresas podem satisfazer melhor seus clientes por meio de qualidade, serviço e valor (KOTLER, 2008), e a satisfação deles é um dos principais objetivos organizacionais, podendo, ainda, ocasionar a lealdade (KUMAR; BATISTA; MAULL, 2011).

Em concordância com Kumar, Batista e Maull (2011), Salleh et al. (2016) destacam que a satisfação do cliente pode de fato contribuir para a lealdade, entretanto, para que isto ocorra, é indispensável haver a percepção de qualidade, com o intuito de evitar falhas no serviço prestado.

Em relação à percepção de qualidade, Lee et al. (2011) realizaram um estudo com jogadores coreanos de golfe e descobriram que os homens avaliaram melhor a qualidade dos serviços dos clubes de golfe que as mulheres. No entanto, Salleh et al. (2016) realizaram um estudo em hotéis na Malásia, e descobriram que os homens relatam mais insatisfação que as mulheres.

Além do gênero, Barrera, García e Moreno (2014) analisaram a percepção de qualidade em relação a serviços on-line e compararam com outras variáveis: idade, nível de escolaridade e frequência de uso. Os autores descobriram que não existem diferenças de percepção de qualidade entre distintos gêneros, pessoas mais jovens e com mais de 24 anos de idade, pessoas com menor ou maior nível de escolaridade, e a frequência de uso ao acesso a sites.

Em relação ao local de nascimento, outra variável aqui pesquisada, não se encontrou trabalhos que verificassem sua influência sobre a percepção de qualidade. No entanto, Grigg et al. (2015) destacaram que o local de nascimento da pessoa pode influenciar de forma complexa a tomada de decisão. Ainda, Ejermo e Hansen (2015), mesmo não pesquisando consumidores, verificaram que o local de nascimento tende a influenciar o pensamento das pessoas. Em seus estudos, Ejermo e Hansen (2015) constataram que o local de nascimento pode influenciar nas escolhas profissionais.

Na prática, consumidores normalmente deparam com uma grande quantidade de produtos e serviços capazes de lhes satisfazer determinada necessidade, sendo que eles formam expectativas em relação ao valor e à satisfação que várias ofertas proporcionarão e fazem suas escolhas de acordo com essas expectativas. Clientes satisfeitos compram novamente e contam aos outros suas boas experiências. Já os insatisfeitos, muitas vezes, mudam para a concorrência e depreciam os produtos da 
empresa (KOTLER; ARMSTRONG, 2007). Matos et al. (2006) reforçam que a satisfação do cliente tende a fazer que ele compre novamente da empresa

Além da recompra, consumidores satisfeitos confiam mais na empresa e sentemse mais apegados a ela (SONG; HUR; KIM, 2012). Portanto, é importante que os gestores procurem satisfazer seus clientes, já que isso pode levar a empresa a obter melhores resultados financeiros em tempo futuro.

A satisfação do cliente deve ocorrer bem antes; nesse caso, empresas precisam primar, no começo, pela satisfação dos que ainda não compraram nela, ou seja, consumidores em geral e stakeholders, já que a influência e as ações destes fortalecem a empresa (HARRISON; BOSSE; PHILLIPS, 2010).

Assim sendo, torna-se pertinente que os administradores façam a medição da satisfação dos consumidores em geral, especialmente buscando analisar se eles percebem qualidade nos estabelecimentos em que compram. Em relação a esse aspecto, algumas escalas foram desenvolvidas, as quais serão destacadas a seguir.

\subsection{Escalas para a Medição da Qualidade}

Lopes, Hernadez e Nohara (2009) salientam que o ambiente competitivo no varejo está mudando rapidamente, já que em geral, intensifica a competição entre empresas varejistas, inclusive multinacionais, sendo hoje comum existir nesse setor incorporações e aquisições, o que o torna ainda mais dinâmico. Esse processo faz que o cliente reaja no mundo das inovações, já que atualmente, um cliente pode percorrer uma loja livremente fazendo seu próprio percurso, muitas vezes, encontrando a mercadoria que quer de forma autônoma, interagindo com diversos funcionários da empresa, devolvendo e trocando mercadorias, entre outras características específicas que influenciam a avaliação da qualidade dos serviços sob a ótica dos clientes (LOPES; HERNADEZ; NOHARA, 2009).

A qualidade nos serviços prestados é uma das importantes preocupações do marketing. Prova disso é que importantes escalas foram feitas e adaptadas para testar a qualidade do nível de serviços oferecidos ao consumidor, como a SERVQUAL Service Quality Scale (PARASURAMAN; ZEITHAML; BERRY, 1985, 1988; PARASURAMAN; BERRY; ZEITHAML, 1991), a SERVPERF - Performance Component of the Service Quality (CRONIN; TAYLOR, 1992) - e a recente RSQ Retail Service Quality (DABHOLKAR; THORPE; RENTZ, 1996). 
Para este trabalho, optou-se pela escala RSQ, já que ela surgiu pela necessidade de não haver uma escala com a amplitude necessária para a mensuração da percepção de qualidade dos serviços em qualquer segmento de negócios (DABHOLKAR; THORPE; RENTZ, 1996). Desde a divulgação da escala RSQ, em 1996, ela é utilizada como ferramenta para o aprofundamento do conhecimento sobre a qualidade percebida de serviço, especialmente em operações varejistas ao redor do mundo (LOPES; HERNADEZ; NOHARA, 2009).

A escolha pela escala RSQ reforça-se pelo fato de ela ser mais moderna que a SERQUAL e SERVPER e, principalmente, mais adequada para a pesquisa de satisfação no varejo, conforme destacam Dabholkar, Thorpe e Rentz (1996) e Lopes, Hernadez e Nohara (2009). Para esses autores, tanto a SERQUAL quanto a SERVPER não são tão apropriadas para mensurar o varejo. Por esses motivos, optou-se pela escala RSQ.

\section{PROCEDIMENTOS METODOLÓGICOS}

A metodologia utilizada para esta pesquisa foi dos tipos quantitativa e descritiva, já que se empregou uma escala validada por Dabholkar, Thorpe e Rentz (1996) para medir a qualidade dos estabelecimentos comerciais na ótica de consumidores de Balsas/MA. A escala RSQ foi ajustada para o contexto da pesquisa, originando o instrumento de coleta. O principal ajuste foi o direcionamento das perguntas para um contexto local e específico - neste caso, o comércio de Balsas, onde se incluem as palavras "o comércio de Balsas" em cada item de mensuração da escala.

Após os ajustes, realizou-se um pré-teste no dia 9 de novembro de 2011 com acadêmicos do curso de Administração da Unibalsas, em uma turma de 27 alunos. $\mathrm{O}$ intuito foi verificar se a tradução da escala original e sua adaptação foram bem realizadas. Após o pré-teste, percebeu-se que todas as perguntas foram compreendidas pelos acadêmicos. Com isso, o instrumento de coleta foi utilizado sem haver alterações na sua primeira versão.

Na sequência, realizou-se a pesquisa de campo, na qual os dados foram obtidos por meio de amostra por conveniência entre os dias 11 e 19 de novembro de 2011, tendo os consumidores sido abordados em ambiente de compra no comércio local de Balsas, MA, definindo-se como área o centro da cidade. Cabe ressaltar que o centro da cidade é composto de pequenos estabelecimentos comerciais, e os entrevistados foram 
convidados a preencher o instrumento de coleta utilizado para esta pesquisa.

A amostra para este levantamento envolveu 248 entrevistados, número que supera o limite mínimo aconselhado por Hair Jr. et al. (2005), de cinco respondentes por questão, já que a escala utilizada continha 28 itens de mensuração e, nesse caso, deveria ser uma amostra com no mínimo 140 respondentes. Os dados foram tabulados no SPSS versão 20.

Para a análise dos dados, utilizou-se estatística descritiva, análise fatorial exploratória, teste de confiabilidade, correlação, teste-t e ANOVA. A estatística descritiva permitiu especialmente conhecer o perfil dos respondentes, além de demonstrar o desempenho dos itens e construtos. A análise fatorial exploratória possibilitou analisar a representatividade dos itens de acordo com as dimensões da escala original. O teste de confiabilidade permitiu verificar se os itens e as dimensões seriam capazes de representar o que se propuseram a medir. A correlação foi usada no sentido de analisar as relações entre as dimensões. Por fim, teste-t e a ANOVA foram capazes de testar as diferenças entre a percepção de qualidade e o perfil dos respondentes.

\section{ANÁLISE DOS RESULTADOS}

Aqui serão demonstrados os resultados obtidos com a pesquisa de campo, que são visualizados por meio de tabelas. $\mathrm{Na}$ primeira parte, serão apresentados os resultados das variáveis categóricas e, na sequência, das variáveis métricas, neste caso, a escala e seus resultados.

\subsection{Perfil dos Respondentes}

O perfil dos respondentes foi identificado por meio das seguintes variáveis: gênero, faixa etária, escolaridade, local de nascimento e tempo de residência na cidade.

Em relação ao gênero, $52,4 \%$ dos respondentes são homens e 47,6\% mulheres. $32,7 \%$ têm até 25 anos de idade, $30,2 \%$ têm entre 26 e 35 anos, $19,8 \%$ têm entre 36 e 45 anos, 12,5\% têm entre 46 e 55 anos e 4,8\% mais de 55 anos. Em relação à escolaridade, $5,6 \%$ possuem ensino básico incompleto, $8,9 \%$ ensino básico completo, $22,2 \%$ ensino médio incompleto, 16,9\% ensino médio completo, 40,3\% ensino superior incompleto, $5,6 \%$ ensino superior completo e apenas $0,4 \%$ têm pós-graduação completa. 
Os demais resultados são apresentados a seguir por meio de tabelas ilustrativas.

Tabela 1 - Nascimento em Balsas

\begin{tabular}{cc|c|c}
\hline \multicolumn{2}{c|}{ Variáveis } & Frequência & Percentual \\
\hline Sim & 184 & 73,4 \\
Não & & 66 & 26,6 \\
\hline \multirow{2}{*}{ Total } & 250 & 100,0 \\
\hline
\end{tabular}

Fonte: dados da pesquisa.

A Tabela 1 demonstra que $26,6 \%$ dos entrevistados não nasceram na cidade, $o$ que confirma o fato de Balsas ter muitos habitantes de outras localidades.

Tabela 2 - Tempo de Residência em Balsas

\begin{tabular}{|c|c|c|}
\hline Variáveis & Frequência & Percentual \\
\hline Mais de 4 anos & 36 & 14,5 \\
\hline Entre 2 e 4 anos & 21 & 8,5 \\
\hline Menos de 2 anos & 9 & 3,6 \\
\hline Total & 66 & 26,6 \\
\hline
\end{tabular}

Fonte: dados da pesquisa.

A Tabela 2 ilustra que a maioria das pessoas que não nasceram em Balsas está residindo na cidade há mais de quatro anos. A seguir serão apresentadas as variáveis métricas utilizadas para a medição da qualidade dos serviços.

\subsection{Satisfação dos Consumidores}

Inicialmente, serão apresentados os resultados das médias dos itens. Na sequência, será visualizada sua confiabilidade e a média de cada dimensão, seguindo a escala original.

\subsubsection{Resultado das médias}

Para medir os resultados, utilizou-se escala de Likert de 9 pontos, a mesma usada no Brasil por Lopes, Hernandez e Nohara (2009) em lojas de São Paulo. A escala aqui utilizada foi de 1 - discordo totalmente até... 9 - concordo totalmente. 
A primeira avaliação será da média dos itens e, em seguida, será apresentado o resultado da média dos construtos.

Tabela 3 - Resultado das Médias dos Itens

\begin{tabular}{|c|c|c|c|c|c|c|}
\hline Item & Núm. & Mínimo & Máximo & Média & Desvio padrão & Escore Fatorial \\
\hline P28 & 248 & 1 & 9 & 5,43 & 2,238 & 0,527 \\
\hline P1 & 248 & 1 & 8 & 5,06 & 1,755 & 0,493 \\
\hline P9 & 248 & 1 & 9 & 5,06 & 1,890 & 0,733 \\
\hline P4 & 248 & 1 & 9 & 4,98 & 1,895 & 0,634 \\
\hline P5 & 247 & 1 & 9 & 4,98 & 1,915 & 0,669 \\
\hline P7 & 248 & 1 & 9 & 4,97 & 1,803 & 0,675 \\
\hline $\mathrm{P} 2$ & 248 & 1 & 9 & 4,97 & 1,921 & 0,516 \\
\hline P14 & 248 & 1 & 9 & 4,97 & 1,944 & 0,707 \\
\hline P8 & 248 & 1 & 9 & 4,94 & 1,837 & 0,725 \\
\hline P15 & 248 & 1 & 9 & 4,92 & 2,074 & 0,744 \\
\hline P10 & 246 & 1 & 9 & 4,92 & 1,915 & 0,687 \\
\hline P3 & 248 & 1 & 9 & 4,90 & 1,843 & 0,564 \\
\hline P13 & 248 & 1 & 9 & 4,88 & 2,013 & 0,752 \\
\hline P16 & 248 & 1 & 9 & 4,83 & 1,907 & 0,710 \\
\hline P24 & 247 & 1 & 9 & 4,83 & 2,004 & 0,692 \\
\hline P11 & 248 & 1 & 9 & 4,82 & 1,894 & 0,717 \\
\hline P6 & 248 & 1 & 9 & 4,82 & 1,776 & 0,752 \\
\hline P27 & 248 & 1 & 9 & 4,79 & 2,343 & 0,562 \\
\hline P12 & 247 & 1 & 9 & 4,77 & 1,986 & 0,782 \\
\hline P26 & 248 & 1 & 9 & 4,75 & 2,175 & 0,614 \\
\hline P18 & 248 & 1 & 9 & 4,74 & 1,908 & 0,729 \\
\hline P22 & 248 & 1 & 9 & 4,67 & 2,007 & 0,676 \\
\hline P20 & 248 & 1 & 9 & 4,66 & 1,928 & 0,733 \\
\hline P25 & 248 & 1 & 9 & 4,66 & 2,197 & 0,623 \\
\hline P19 & 248 & 1 & 9 & 4,65 & 1,994 & 0,740 \\
\hline P21 & 248 & 1 & 9 & 4,65 & 1,956 & 0,699 \\
\hline P17 & 248 & 1 & 9 & 4,64 & 1,956 & 0,716 \\
\hline P23 & 248 & 1 & 9 & 4,49 & 2,070 & 0,671 \\
\hline
\end{tabular}

Revista Eletrônica Gestão e Serviços v.7, n. , pp.1602-1623, Julho/Dezembro 2016. ISSN Online: 2177-7284 e-mail: regs@metodista.br 


\begin{tabular}{l|c|c|c}
\hline Resultado geral & 4,85 & - & \\
\hline
\end{tabular}

Fonte: dados da pesquisa.

Pode-se perceber que os itens tiveram uma avaliação entre 4,49 e 5,43, quase todos em torno de 5, em uma escala de 1 a 9 . A confirmação de que o comércio em Balsas não ocasiona plena qualidade por parte dos entrevistados pode ser percebida pelo resultado da média das médias, que foi 4,85 , o que novamente representa uma avaliação mediana, em torno de 5.

Assim sendo, verifica-se que de forma geral, os estabelecimentos comerciais da cidade não oferecem qualidade à população, contrariando a expectativa de Longenecker et al. (1997), Kotler (2008), Lauga e Ofek (2011) e Melo et al. (2012). Para Longenecker et al. (1997), empresas devem prestar serviços com excelência. De acordo com Kotler (2008), elas devem investir na qualidade para satisfazer seus consumidores. Lauga e Ofek (2011) enfatizam a necessidade de haver percepção de qualidade pelos consumidores. Melo et al. (2012) complementam as contribuições de Lauga e Ofek (2011), destacando que consumidores, quando se sentirem bem no local onde compram, ocasionam benefícios pessoais e organizacionais por meio dessa satisfação.

Os três melhores resultados das 28 perguntas da escala RSQ que medem a qualidade do serviço no comércio varejista são: P28 (O comércio em Balsas oferece seus próprios cartões de crédito), com média de 5,43, P1 (As lojas de comércio em Balsas têm equipamentos e mobiliários modernos), com média de 5,06, e P9 (Os estabelecimentos comerciais de Balsas realizam os serviços de maneira correta na primeira vez), com média de 5,06. Chama a atenção que o item mais bem avaliado foi o único que ficou próximo de 5,5, confirmando de fato que o oferecimento de crédito pelas lojas é visto como um item positivo pelos consumidores entrevistados.

Os três piores resultados das 28 perguntas da escala RSQ são: P23 (No comércio em Balsas, os empregados das lojas são habilitados a solucionar imediatamente as reclamações por parte do cliente) com média de 4,65, P17 (No comércio em Balsas, os empregados prestam informações corretas sobre os prazos em que os serviços serão realizados), com uma média de 4,64, e P21 (No comércio em Balsas, os empregados sempre estão disponíveis para sanar as dúvidas dos clientes), com média de 4,49, sendo esses os três itens que requerem maior atenção por parte dos estabelecimentos comerciais.

Revista Eletrônica Gestão e Serviços v.7, n. , pp.1602-1623, Julho/Dezembro 2016.

ISSN Online: 2177-7284 e-mail: regs@metodista.br 
Os resultados, principalmente os itens avaliados menos positivamente, vão ao encontro da pesquisa realizada por Viapiana (2000), pois elucidam a importância do bom atendimento ao cliente, e os três piores desempenhos são alusivos a esse tema.

Já os três itens que apresentam maiores escores fatoriais são: P12 (Os empregados do comércio em Balsas possuem conhecimento necessário para responder às dúvidas dos clientes), P13 (No comércio em Balsas, o comportamento dos funcionários inspira confiança aos clientes) e P6 (O layout [tráfego interno e localização dos produtos] dos estabelecimentos comerciais de Balsas facilita a locomoção do cliente). Neste caso, esses itens seriam aqueles que "carregaram" mais informação; ou seja, são os mais representativos para representar a qualidade nos serviços. Portanto, de acordo com os entrevistados, um estabelecimento comercial precisa responder às dúvidas dos clientes, transparecer confiança aos clientes e possuir um layout que facilite a locomoção.

$\mathrm{Na}$ sequência, se verificarão a média e a confiabilidade de cada uma das cinco dimensões da escala.

\subsubsection{Confiabilidade e média das dimensões}

A confiabilidade dos construtos originais da escala de Dabholkar, Thorpe e Rentz (1996) foi medida pelo alpha de cronbach. Também realizou-se a análise fatorial exploratória por dimensão no sentido de analisar a representatividade de cada item por meio da carga fatorial. A rotação adotada foi a Varimax por ser uma rotação usualmente utilizada em marketing. Os resultados estão expostos na Tabela 4.

Tabela 4 - Análise Fatorial Exploratória (Comunalidades), Média das Dimensões e Confiabilidade (Alpha de Cronbach)

\begin{tabular}{l|c|c|c}
\hline \multicolumn{1}{c|}{ Item } & Comunalidades & $\begin{array}{c}\text { Dimensões e } \\
\text { médias }\end{array}$ & $\begin{array}{c}\text { Alpha de } \\
\text { Cronbach }\end{array}$ \\
\cline { 1 - 2 } P1 (equipamentos e mobiliários modernos) & 0,599 & & \multirow{2}{*}{ Aspectos físicos } \\
P2 (ambiente visualmente agradável) & 0,738 & \multirow{2}{*}{0,879} \\
P3 (materiais visualmente agradáveis) & 0,698 & \\
\cline { 1 - 2 } P4 (limpeza adequada) & 0,650 & & \\
\cline { 1 - 2 } P5 (layout facilita encontrar o produto) & 0,704 & & \\
\hline
\end{tabular}

Revista Eletrônica Gestão e Serviços v.7, n. , pp.1602-1623, Julho/Dezembro 2016. ISSN Online: 2177-7284 e-mail: regs@metodista.br 


\begin{tabular}{|c|c|c|c|}
\hline P7 (cumprimento dos prazos informados) & 0,656 & \multirow{5}{*}{$\begin{array}{c}\text { Confiança } \\
4,97\end{array}$} & \multirow{5}{*}{0,887} \\
\hline P8 (cumprimento das promessas) & 0,740 & & \\
\hline P9 (realização correta dos serviços pela $1^{\mathrm{a}}$ vez) & 0,772 & & \\
\hline P10 (mercadorias que os clientes desejam) & 0,652 & & \\
\hline P11 (registro de transações sem erros) & 0,623 & & \\
\hline P12 (empregados habilitados para sanar dúvidas) & 0,657 & \multirow{9}{*}{$\begin{array}{c}\text { Interação } \\
\text { pessoal } \\
4,75\end{array}$} & \multirow{9}{*}{0,926} \\
\hline P13 (comportamento confiável dos funcionários) & 0,769 & & \\
\hline P14 (segurança dos clientes na loja) & 0,788 & & \\
\hline P15 (disponibilidade de atender aos clientes) & 0,716 & & \\
\hline $\begin{array}{l}\text { P16 (informações prestadas corretamente ao } \\
\text { cliente) }\end{array}$ & 0,654 & & \\
\hline P17 (disponibilidade para sanar dúvidas do cliente) & 0,663 & & \\
\hline P18 (atendimento personalizado ao cliente) & 0,671 & & \\
\hline P19 (empregados cordiais) & 0,720 & & \\
\hline P20 (empregados cordiais ao telefone) & 0,717 & & \\
\hline P21 (a loja facilita a troca de mercadorias) & 0,712 & \multirow{3}{*}{$\begin{array}{c}\text { Solução de } \\
\text { problemas } \\
4,59\end{array}$} & \multirow{3}{*}{0,842} \\
\hline P22 (interesse em resolver o problema do cliente) & 0,690 & & \\
\hline $\begin{array}{l}\text { P23 (empregados habilitados a solucionar dúvidas e } \\
\text { reclamações) }\end{array}$ & 0,654 & & \\
\hline P24 (produtos de alta qualidade) & 0,620 & \multirow{5}{*}{$\begin{array}{c}\text { Políticas } \\
\text { internas } \\
4,81\end{array}$} & \multirow{5}{*}{0,834} \\
\hline P25 (amplo estacionamento) & 0,634 & & \\
\hline P26 (horário de funcionamento conveniente) & 0,645 & & \\
\hline P27 (aceitação da maioria dos cartões de crédito) & 0,679 & & \\
\hline P28 (oferecimento de seu próprio cartão de crédito) & 0,556 & & \\
\hline
\end{tabular}

Fonte: dados da pesquisa.

Analisando a Tabela 4, inicialmente percebe-se que todos os itens apresentam índices de comunalidades adequados (maior que 0,5 pela indicação de Hair Jr. et al., 2005). Constatou-se ainda, que nenhum item apresentou carga fatorial abaixo do índice sugerido por Hair Jr. et al. (2005); não havendo portanto, a necessidade de exclusão de itens por representatividade insuficiente.

Em relação aos construtos, observou-se que eles apresentaram um alpha maior do que 0,8 , recomendado por Hair Jr. et al. (2005), o que indica que todos os itens Revista Eletrônica Gestão e Serviços v.7, n. , pp.1602-1623, Julho/Dezembro 2016. ISSN Online: 2177-7284 e-mail: regs@metodista.br 
podem representar com propriedade os cinco construtos investigados na escala. Verifica-se, ainda, que houve certa paridade nas médias dos construtos, pois ficaram entre 4,5 e 5, o que demonstra um resultado mediano. O construto que mais se destacou foi a confiança, seguido dos aspectos físicos. No entanto, mais uma vez cabe ressaltar que as médias ficaram próximas, o que elucida uma avaliação sem discrepância entre as dimensões.

Sob forma de melhor compreender a relação das dimensões da escala original, realizou-se a matriz de correlação, apresentada na Tabela 5.

Tabela 5 - Matriz de Correlação

\begin{tabular}{l|l|r|r|r|r|r}
\hline \multicolumn{1}{c|}{ Dimensões } & \multicolumn{1}{c|}{ Correlação } & $\begin{array}{c}\text { Aspectos } \\
\text { Físicos }\end{array}$ & Confiança & $\begin{array}{c}\text { Interação } \\
\text { Pessoal }\end{array}$ & $\begin{array}{c}\text { Solução } \\
\text { de } \\
\text { Problemas }\end{array}$ & \multicolumn{1}{c}{$\begin{array}{c}\text { Políticas } \\
\text { Internas }\end{array}$} \\
\hline \multirow{2}{*}{ Aspectos Físicos } & Correlação de Pearson & 1 & $1,000^{* *}$ & $0,565^{* *}$ & $0,412^{* *}$ & $0,443^{* *}$ \\
& Sig. (2 extremidades) & & 0,000 & 0,000 & 0,000 & 0,000 \\
Confiança & Correlação de Pearson & $1,000^{* *}$ & 1 & $0,565^{* *}$ &, $412^{* *}$ & $0,443^{* *}$ \\
& Sig. (2 extremidades) & 0,000 & & 0,000 & 0,000 & 0,000 \\
Interação Pessoal & Correlação de Pearson & $0,565^{* *}$ & $0,565^{* *}$ & 1 & $0,661^{* *}$ & $0,518^{* *}$ \\
\multirow{3}{*}{ Solução de } & Sig. (2 extremidades) & 0,000 & 0,000 & & 0,000 & 0,000 \\
Problemas & Correlação de Pearson & $0,412^{* *}$ & $0,412^{* *}$ & $0,661^{* *}$ & 1 & $0,633^{* *}$ \\
\multirow{2}{*}{ Políticas Internas } & Sig. (2 extremidades) & 0,000 & 0,000 & 0,000 & & 0,000 \\
& Correlação de Pearson & $0,443^{* *}$ & $0,443^{* *}$ & $0,518^{* *}$ & $0,633^{* *}$ & 1 \\
& Sig. (2 extremidades) & 0,000 & 0,000 & 0,000 & 0,000 & \\
\hline
\end{tabular}

**. A correlação é significativa no nível 0,01 (2 extremidades).

Fonte: dados da pesquisa.

A Tabela 5 apresenta a correlação entre as dimensões. Evidencia-se que a correlação mais intensa é entre solução de problemas e políticas internas. Com um pouco menos de intensidade, verificou-se a relação entre interação pessoal e resolução de problemas.

Portanto, pode-se constatar que a solução de problemas depende da interação que as pessoas possuem e das políticas internas adotadas. Assim, vislumbra-se a necessidade da existência de três vertentes objetivando a qualidade dos serviços: políticas, pessoas e soluções de problemas. 


\subsubsection{Análise de cruzamentos}

Para uma melhor compreensão dos dados pesquisados, realizaram-se cruzamentos de todas as variáveis categóricas com a média geral das médias. O primeiro cruzamento refere-se ao gênero.

Tabela 6 - Satisfação do Consumidor conforme o Gênero

\begin{tabular}{l|c|c}
\hline \multicolumn{1}{c|}{ Gênero } & Média & Teste T \\
\hline Feminino & 4,73 & 0,599 \\
\hline Masculino & 4,83 & \\
\hline
\end{tabular}

Fonte: dados da pesquisa.

A Tabela 6 demonstra que as médias entre mulheres e homens foram muito próximas. $\mathrm{O}$ teste-T confirma que não há diferença estatística entre os gêneros (sig. > 0,05). Isso quer dizer que homens e mulheres avaliam igualmente a qualidade do comércio de Balsas, MA. Os resultados contrariam os estudo de Lee et al. (2011) e Salleh et al. (2016) e corroboram com os achados de Barrera, García e Moreno (2014). O próximo cruzamento testa a faixa etária.

Tabela 7 - Satisfação do Consumidor conforme a Faixa Etária

\begin{tabular}{l|c|c}
\multicolumn{1}{c|}{ Faixa etária } & Média & ANOVA \\
\hline Até 25 anos & 4,69 & \\
\hline Entre 26 e 35 anos & 4,95 & \multirow{2}{*}{0,600} \\
\hline Entre 36 anos e 45 anos & 4,86 & \\
\hline Entre 46 e 55 anos & 4,74 & \\
\hline Mais de 55 anos & 4,02 & \\
\hline
\end{tabular}

Fonte: dados da pesquisa.

A Tabela 7 evidencia que não há diferenças de percepção de qualidade em relação à faixa etária pelo teste $\operatorname{ANOVA}(\mathrm{t}>0,05)$. Neste caso, pode-se dizer que a população, independente da sua idade, avalia o comércio de Balsas-MA de forma igualitária, indo ao encontro dos resultados de Barrera, García e Moreno (2014).

Revista Eletrônica Gestão e Serviços v.7, n. , pp.1602-1623, Julho/Dezembro 2016. ISSN Online: 2177-7284 e-mail: regs@,metodista.br 
O próximo cruzamento aborda o tempo de residência na cidade e a satisfação com o comércio.

Tabela 8 - Satisfação dos Consumidores conforme o Local de Nascimento

\begin{tabular}{l|c|c}
\hline \multicolumn{1}{c|}{ Local de nascimento } & Média & Teste T \\
\hline Na cidade & 4,86 & 0,765 \\
\hline Em outra cidade & 4,80 & \\
\hline
\end{tabular}

Fonte: dados da pesquisa.

Os resultados indicam que as pessoas que não nasceram em Balsas-MA avaliam de uma forma menos positiva o comércio local, indicando que são pessoas mais críticas ou mais exigentes. No entanto, essas diferenças não foram significativas pelo teste-T $(\mathrm{t}$ $>0,05)$, o que indica que o local de nascimento não interfere na percepção da qualidade do comércio.

Ejermo e Hansen (2015) demonstraram que o local de nascimento pode influenciar na escolha profissional. Neste estudo, o local de nascimento não se evidenciou, em princípio, influenciador para provocar diferente percepção de qualidade. Cabe ressaltar que não se analisou o tempo de residência das pessoas que não nasceram na cidade, de repente, mesmo não nascendo, um considerável número de pessoas pode ter se criado na cidade e adquirido com facilidade hábitos e costumes locais.

A seguir, foi avaliado o grau de escolaridade.

Tabela 9 - Satisfação dos Consumidores conforme seu Grau de Escolaridade

\begin{tabular}{l|c|c}
\hline \multicolumn{1}{c|}{ Tempo de residência em Balsas } & Média & ANOVA \\
\hline Ensino fundamental/primário & 4,15 & \multirow{2}{*}{0,000} \\
\hline Ensino médio & 5,17 & \\
\hline Ensino superior/pós & 4,34 & \\
\hline
\end{tabular}

Fonte: dados da pesquisa.

A Tabela 9 ilustra que as pessoas de menor escolaridade avaliaram mais negativamente a qualidade do comércio. Cabe ressaltar que nessa faixa se encontram as pessoas de ensino básico completo e incompleto. No ensino médio foram incluídos os 
que estão cursando esse nível ou o concluíram, mas não ingressaram ainda no ensino superior. Por fim, o ensino superior/pós inclui desde acadêmicos até diplomados, realizando ou não a pós-graduação. Essa junção se fez necessária devido ao pequeno número de pessoas com ensino básico incompleto e com o ensino superior e pósgraduação completos, o que poderia dar um viés de análise.

$\mathrm{O}$ teste de ANOVA demonstra que essa diferença é significativa (sig. <0,05). O teste de Tukey confirma que a diferença existe em relação aos que possuem ensino fundamental/primário comparando com os demais. Nesse caso, afirma-se que pessoas de menor escolaridade avaliaram mais negativamente a qualidade do comércio.

Os resultados contrariam as evidências de Barrera, García e Moreno (2014), os quais encontraram uma regularidade de percepção de qualidade em pessoas de diferentes níveis de escolaridade.

O último cruzamento aborda o tempo de residência na cidade e a satisfação com o comércio. Essa pergunta foi direcionada aos que não nasceram na cidade. O resultado é exposto na Tabela 10.

Tabela 10 - Satisfação dos Consumidores conforme o Tempo de Residência na Cidade

\begin{tabular}{l|c|c}
\hline \multicolumn{1}{c|}{ Tempo de residência em Balsas } & Média & ANOVA \\
\hline Menos de 2 anos & 5,00 & \multirow{2}{*}{0,112} \\
\hline Entre 2 e 4 anos & 5,19 & \\
\hline Mais de 4 anos & 4,34 & \\
\hline
\end{tabular}

Percebe-se que a menor avaliação foi assinalada pelos moradores que estão há mais de quatro anos na cidade. No entanto, o teste de ANOVA demonstra que essa diferença não é significativa (sig. > 0,05).

Esses achados demonstram que o tempo de contato com a cidade não influencia a percepção de qualidade. Barrera, García e Moreno (2014) pesquisaram essa relação levando em conta o contato do consumidor com sites, visto que seu estudo tinha por objetivo analisar a percepção da qualidade de ensino em consumidores on-line. Seus estudos confirmaram que, independente do tempo (mais ou menos frequência de uso), consumidores possuem o mesmo nível de qualidade. Resultados parecidos foram encontrados aqui, demonstrando que o tempo de contato com o local não influencia no 
nível de percepção de qualidade.

\section{CONSIDERAÇÕES FINAIS}

Uma das grandes preocupações do trabalho não foi somente medir o nível de percepção de qualidade dos consumidores locais, mas como fazer essa medição. Portanto, buscou-se utilizar uma escala já validada, neste caso a RSQ, uma escala nova e pouco usada no Brasil, que mais uma vez demonstrou ser eficiente para a medição do varejo local.

Após a aplicação da escala no comércio de Balsas, MA, percebeu-se que os consumidores não percebem a qualidade dos estabelecimentos comerciais da cidade, já que, ao final, se obteve um resultado médio de 4,85 em todos os 28 itens avaliados, em uma escala Likert de 1 a 9 pontos. Esse achado não confirma as ideias de Longenecker et al. (1997), que manifestaram ser possível pequenas empresas oferecerem serviços de excelência.

Os três melhores resultados de satisfação foram: o comércio em Balsas oferece seus próprios cartões de crédito, sendo este o mais bem avaliado; as lojas de comércio em Balsas têm equipamentos e mobiliários modernos; e os estabelecimentos comerciais de Balsas realizam os serviços de maneira correta na primeira vez. Chama a atenção a importância de oferecer o próprio cartão de crédito, indo de encontro com a pesquisa de Borges et al. (2013). Também é importante atender bem o cliente na primeira vez e possuir equipamentos e mobiliários modernos. O último item corrobora os achados de Viapiana (2000) ao enfatizar a importância da aparência de um leiaute agradável ao cliente.

Em relação às dimensões, percebeu-se que foi a confiança por parte dos entrevistados a que se destacou mais, e a que menos se destacou foi a solução de problemas. No que diz respeito a uma relação entre elas, constatou-se que três possuem relação entre si: políticas internas, interação pessoal e resolução de problemas. Neste caso, torna-se relevante que os estabelecimentos comerciais foquem em políticas, relação entre as pessoas e soluções de problemas. No geral, todos os construtos tiveram uma avaliação mediana, assim como os itens.

Realizou-se, ainda, análise de diferenças por meio do teste-T e ANOVA, e percebeu-se que pessoas de menor escolaridade avaliaram mais negativamente a 
qualidade do comércio. Não foram encontradas outras diferenças estatísticas. Chama a atenção o fato de que o local de nascimento e o tempo de residência na cidade não fazem que os consumidores pensem diferente na hora de avaliar o comércio de Balsas. Esses resultados levam a crer que o tempo de moradia na cidade não é uma variável que determine diferença nas opiniões, ou seja, moradores advindos de outras cidades, com o tempo, passam a perceber a qualidade do comércio de igual forma que os nativos.

Como contribuição científica, o trabalho demonstrou que a confiança por parte do cliente parece o principal caminho para a existência da percepção de qualidade. Ademais, constatou-se haver relação entre políticas internas e resolução de problemas, interação pessoal e resolução de problemas. Os resultados sugerem que a resolução de problemas seja dependente das políticas e da atuação das pessoas na empresa. Outro achado científico relevante é o fato de que a qualidade demonstra ter um nível igualitário na percepção do consumidor, mesmo entendendo a existência de diferenças pessoais.

Em temos de contribuições gerenciais, percebe-se que os comerciantes devem oferecer suas próprias opções de créditos, buscar tratar bem o cliente no primeiro momento e possuir ambiente e mobiliário atraentes. Outro detalhe importante é o bom atendimento e a percepção de confiança por parte do cliente. Ações como essas podem fazer que os consumidores avaliem melhor o comércio de sua cidade e, por conseguinte, comprem no comércio de sua cidade e o valorizem mais, contribuindo para o desenvolvimento regional.

Destaca-se ainda como contribuição empírica, o fato de existir uma indicação, de acordo com a pesquisa, sobre a possibilidade de empresas comerciais se atentarem para a existência de três vertentes objetivando a qualidade dos serviços: políticas, pessoas e soluções de problemas.

\subsection{Limitações e Sugestões}

A principal limitação do estudo é o fato de ter sido utilizada uma amostra não probabilística. Entretanto, cabe ressaltar que amostras não probabilísticas, neste caso por conveniência, são amplamente usadas em pesquisas de administração. Como sugestão, recomenda-se a aplicação da escala em outro contexto, assim como uma pesquisa mais aprofundada para verificar se, de fato, pessoas com menor escolaridade são mais exigentes em relação à qualidade prestada pelas lojas de varejo. Recomendam- 
se também estudos similares em outras localidades e com a mesma escala para verificar a similaridade de respostas.

\section{REFERENCIAS}

BARNEY, Jay B.; CLARK, Delwyn N. Resource-Based Theory: Creating and Sustaining Competitive Advantage. New York: Oxford, 2007.

BARRERA, Ramón Barrera; GARCÍA, Antonio Navarro; MORENO, Manuel Rey. Evaluation of the e-service quality in service encounters with incidents: Differences according to the socio-demographic profile of the online consumer. Revista Europea de Dirección y Economía de la Empresa, v. 23, n. 4, p. 184-193, 2014.

BARROS, Aluízio Antonio de; PEREIRA, Cláudia Maria Miranda de.

Empreendedorismo e Crescimento Econômico: uma análise empírica. RAC, v. 12, n. 4, p. 975-993, out./dez., 2008.

BORGES, Gustavo da Rosa; SILVA, Renata Gonçalves Santos; SINDELAR, Fernanda Cristina Wiebusch; MIORANZA, Gustavo. Identificando motivos de compras em pequenos estabelecimentos de varejo localizados próximos a grandes concorrentes.

Estudo \& Debate, v. 20, n. 1, p. 39-54, 2013.

CHINEM, RIVALDO. Marketing e divulgação da pequena empresa. São Paulo: Senac, 2001.

CRONIN, J. J.; TAYLOR, S. A. Measuring service quality: a reexamination and extension. Journal of Marketing, v. 56, n. 3, p. 55-68, 1992.

DABHOLKAR, P. A.; THORPE, D. I.; RENTZ, J. O. A measure of service quality for retail stores: scale development and validation. Journal of the Academy of Marketing Science, v. 24, n. 3, p. 3-16, 1996.

EJERMO, Olof; HANSEN, HøgniKalsø. How important are local inventive milieus: The role of birthplace, high school and university education. Geoforum, v. 65, p. 387397, 2015.

GRIGG, Celia P. et al. Women's birthplace decision-making, the role of confidence: Part of the Evaluating Maternity Units study. New Zealand. Midwifery, v. 31, n. 6, p. 597-605, 2015.

HAIR JR., J. F. et al. Análise Multivariada de Dados, 5. ed., Porto Alegre: Bookman, 2005.

HARRISON, Jeffrey S.; BOSSE, Douglas A.; PHILLIPS, Robert A. Managing for Stakeholders, Stakeholder Utility Functions and Competitive Advantage. Strategic Management Journal, v. 31, p. 58-74, 2010.

KOTLER, Philip. Administração de marketing: análise, planejamento e controle. São Paulo: Atlas, 2008. 
KOTLER, P.; ARMSTRONG, G. Princípios de marketing, 12.ed., São Paulo: Prentice Hall, 2007.

KUMAR, Vikas; BATISTA, Luciano; MAULL, Roger. The Impact of Operations Performance on Customer Loyalty. Service Science, v. 3, n. 2, p. 158-171, 2011.

LAS CASAS, Alexandre Luizzi. Administração de marketing: conceitos, planejamentos e aplicações à realidade brasileira. São Paulo: Atlas, 2010.

LAUGA, Dominique Olié; OFEK, Elie. Product Positioning in a Two-Dimensional Vertical Differentiation Model: The Role of Quality Costs. Marketing Science, v. 30, n. 5, p. 903-923, September-October, 2011.

LEE, Jeoung-Hak et al. The influence of service quality on satisfaction and intention: A gender segmentation strategy. Sport Management Review, v. 14, n. 1, p. 54-63, 2011.

LONGENECKER, J. G.; MOORE, C. W.; PETTY, J. W. Administração de pequenas empresas: ênfase na gerência empresarial. São Paulo: Makron Books, 1997.

LOPES, Evandro Luiz, HERNADEZ, Jose Moura da Costa; NOHARA, Jouliana Jordan. Escalas concorrentes para a mensuração da qualidade percebida: uma comparação entre a Servqual e a RSQ. RAE, São Paulo, n. 4, v. 49, p. 401-416, out./dez., 2009.

MATOS, C. A.; ROSSI, C. A. V.; VEIGA, R. T.; VIEIRA, V. A. Consumer Reaction to Service Failure and Recovery: The Moderating Role of Attitude Toward Complaining. ANAIS do Encontro da ANPAD, 30, Salvador, 23 a 27 de setembro de 2006.

MELO, Daniela de Castro. O Comportamento do Consumidor em Lojas de Varejo: uma investigação de valores com base na teoria da cadeia de meios e fins nas cidades de Uberlândia e Uberaba. Revista Gestão e Planejamento, Salvador, v. 13, n. 2, p. 315334, mai./ago., 2012.

MIZUMOTO, Fábio Matuoka; ARTES, Rinaldo; GIOVANETTI, Sérgio;

HASHIMOTO Lazzarini Marcos; BEDÊ, Marco Aurélio. A sobrevivência de empresas nascentes no Estado de São Paulo: um estudo sobre capital humano, capital social e práticas gerenciais. R. Adm., São Paulo, v. 45, n. 4, p. 343-355, out./nov./dez., 2010.

OLIVEIRA, Edmundo M. A virada dos pequenos. Pequenas Empresas Grandes Negócios. São Paulo, Ano IX, n. 100, p. 37, maio 1997.

PARASURAMAN, A.; BERRY, L. L; ZEITHAML, V. Refinement and reassessment of the ServQual scale. Journal of Retailing, v. 67, n. 4, p. 420-450, 1991.

PARASURAMAN, A.; ZEITHAML, V.; BERRY, L. L. A conceptual model of service quality and its implications for future research. Journal of Marketing, v. 49, n. 2, p. 41-50, 1985.

Revista Eletrônica Gestão e Serviços v.7, n. , pp.1602-1623, Julho/Dezembro 2016.

ISSN Online: 2177-7284 e-mail: $\underline{\text { regs@ @metodista.br }}$ 
PARASURAMAN, A.; ZEITHAML, V.; BERRY, L. L. ServQual: a multiple-item scale for measuring consumer perceptions of service quality. Journal of Retailing, $v$. 64, n. 1, p. 12-40, 1988.

SALLEH, Mohammad ZaimMohd et al. Gender Differences Among Hotel Guest Towards Dissatisfaction with Hotel Services in Kuala Lumpur. Procedia Economics and Finance, v. 37, p. 27-32, 2016.

SONG, Younghee; HUR, Won-Moo; KIM, Minsung. Brand trust and effect in the luxury brand-customer relationship. Social Behavior and Personality, v. 40, n. 2, p. 331-338, 2012.

SOUZA, Maria Carolina de Azevedo Ferreira; MAZZALI, Leonel. Conceito e espaço da pequena empresa na estrutura industrial: heterogeneidade e formas de inserção. Gestão \& Produção, v. 15, n. 3, p. 591-603, 2008.

VIAPIANA, Cláudio. Fatores de sucesso e fracasso da micro e pequena empresa. Tese de Doutorado. Universidade Federal de Santa Catarina, Centro Socioeconômico, 2000 . 